\title{
Karyotype Analysis of Wild Rosa Species in Xinjiang, Northwestern China
}

\author{
Chao Yu, Le Luo, and Hui-tang Pan \\ Beijing Key Laboratory of Ornamental Plants Germplasm Innovation \& Molecular Breeding, Beijing \\ 100083, China; National Engineering Research Center for Floriculture, Beijing 100083, China; and \\ College of Landscape Architecture, Beijing Forestry University, Beijing 100083, China \\ Yun-ji Sui and Run-hua Guo \\ Xinjiang Career Technical College, Xinjiang 833200, China

\begin{abstract}
Jin-yao Wang and Qi-xiang Zhang ${ }^{1}$
Beijing Key Laboratory of Ornamental Plants Germplasm Innovation \& Molecular Breeding, Beijing 100083, China; National Engineering Research Center for Floriculture, Beijing 100083, China; and College of Landscape Architecture, Beijing Forestry University, Beijing 100083, China
\end{abstract}

\begin{abstract}
AdDitional index words. chromosome, ploidy, rose, taxonomy
Abstract. Wild Rosa species, which are highly variable and locally adapted, are widely distributed in the Xinjiang Uygur autonomous region of China. These species possess many important horticultural traits that are not found in the gene pool of modern cultivated roses. However, little is known about their cytological characteristics, because few of them have been karyologically analyzed. Karyological data of 13 samples of seven wild Rosa taxa, including $R$. berberifolia, two botanical varieties of $R$. spinosissima, $R$. platyacantha, $R$. beggeriana, $R$. acicularis, and $R$. laxa, were investigated by means of squashes of shoot tips. The results showed that seven samples were diploid $(2 n=2 x=$ 14), whereas the other six samples were tetraploid $(2 n=4 x=28)$. The karyotypes of all the test samples were composed of $\mathrm{m}$ and sm chromosomes, which include $1 \mathrm{~A}, 2 \mathrm{~A}, 1 \mathrm{~B}$, and $2 \mathrm{~B}$. There were differences in asymmetry index, centromere index, and distribution of relative lengths. The karyotype of the tetraploid $R$. laxa var. laxa sample from Aksu easily distinguished from the other $R$. laxa var. laxa samples tested in having the highest asymmetry index and the most evolved karyotype. This Aksu population merits recognition as a new botanical variety of $R$. laxa. The karyological data, most of which are first reports for their taxa, provide a comprehensive cytogenetic resource that can be used to better understand the taxonomy, evolution, and speciation in the genus Rosa and to identify candidate species for breeding programs.
\end{abstract}

The genus Rosa comprises $\approx 150$ species that are widely distributed in diverse climates and habitats throughout the Northern Hemisphere (Quest-Ritson and Quest-Ritson, 2003; Rehder, 1940) from subtropical to cold-temperate regions. China's 95 species (65 endemic) account for nearly half of the world's Rosa species (Ku and Robertson, 2003). Therefore, China is a center of distribution of Rosa as it is with numerous other cultivated plants (Brichet, 2003), and China's roses are a great genetic resource for rose improvement.

The Xinjiang Uygur autonomous region (hereafter referred to as Xinjiang) lies at the northwestern border of China (Fig. 1). The Tianshan Mountains transverse it centrally, dividing Xinjiang into southern and northern regions, which differ greatly from each other in climate. In regard to phytogeography, Xinjiang spans the junction of the Eurasian Forest subregion, the Eurasian Steppe subregion, and the Central Asiatic Desert subregion. Many of the wild Rosa species in Xinjiang are

Received for publication 7 Aug. 2013. Accepted for publication 25 Nov. 2013. This study was supported by the Ministry of Science and Technology for the Twelfth Five-Year Science and Technology Project, People's Republic of China (Grant No. 2012BAD01B07).

We thank Jian-guo Liang, Hui Xue, Jian-xin Liu, and Yun-hong Wang from Beijing Forestry University for the investigation in Xinjiang; Jaenicke Hannah from the International Society for Horticultural Science, Charles Crane from Purdue University, and Ying-nan Wang and Xue-lian Guo from Beijing Forestry University for their critical review of this manuscript.

${ }^{1}$ Corresponding author. E-mail: zqxbjfu@126.com. distributed widely (Fig. 2). Although 11 Rosa species and three botanical varieties were recorded from Xinjiang in Flora of China [Ku and Robertson, 2003 (Table 1)], further research has indicated that more than 20 species occur in Xinjiang with botanical varieties that exhibit all sorts of morphological characteristics (Bao, 1993; Liu, 1993; Liu and Cong, 2000; Ma and Chen, 1990, 1991; Yu et al., 1985, 2011). These botanical varieties have been described by different investigators and are notoriously difficult to distinguish, owing to the presence of intermediate forms (Han, 1995). In addition, nomenclatural synonyms and the selection and breeding of cultivars have added to the confusion (Macphail and Kevan, 2009).

There is much interest worldwide in the wild Rosa species from China, because they contributed much of the foundation of modern cultivated roses. Wild Rosa species with important traits, such as powdery mildew (Podosphaera pannosa) resistance, large flowers and hips, and cold and drought resistance are regarded as valuable breeding materials. Modern roses are primarily compose of eight to 11 Rosa species and only a few of the species have been involved. Those other species currently are not reported (Ma and Chen, 1992; Zlesak, 2006). Introgressing additional valuable genes from these species into modern rose germplasm is inevitably a long and difficult process (Zlesak et al., 2007), because of the long generation time and the frequent cross-incompatibility and hybrid sterility between parents of different ploidy levels. Therefore, there is interest in the variation of ploidy within and among wild Rosa species. Despite the 


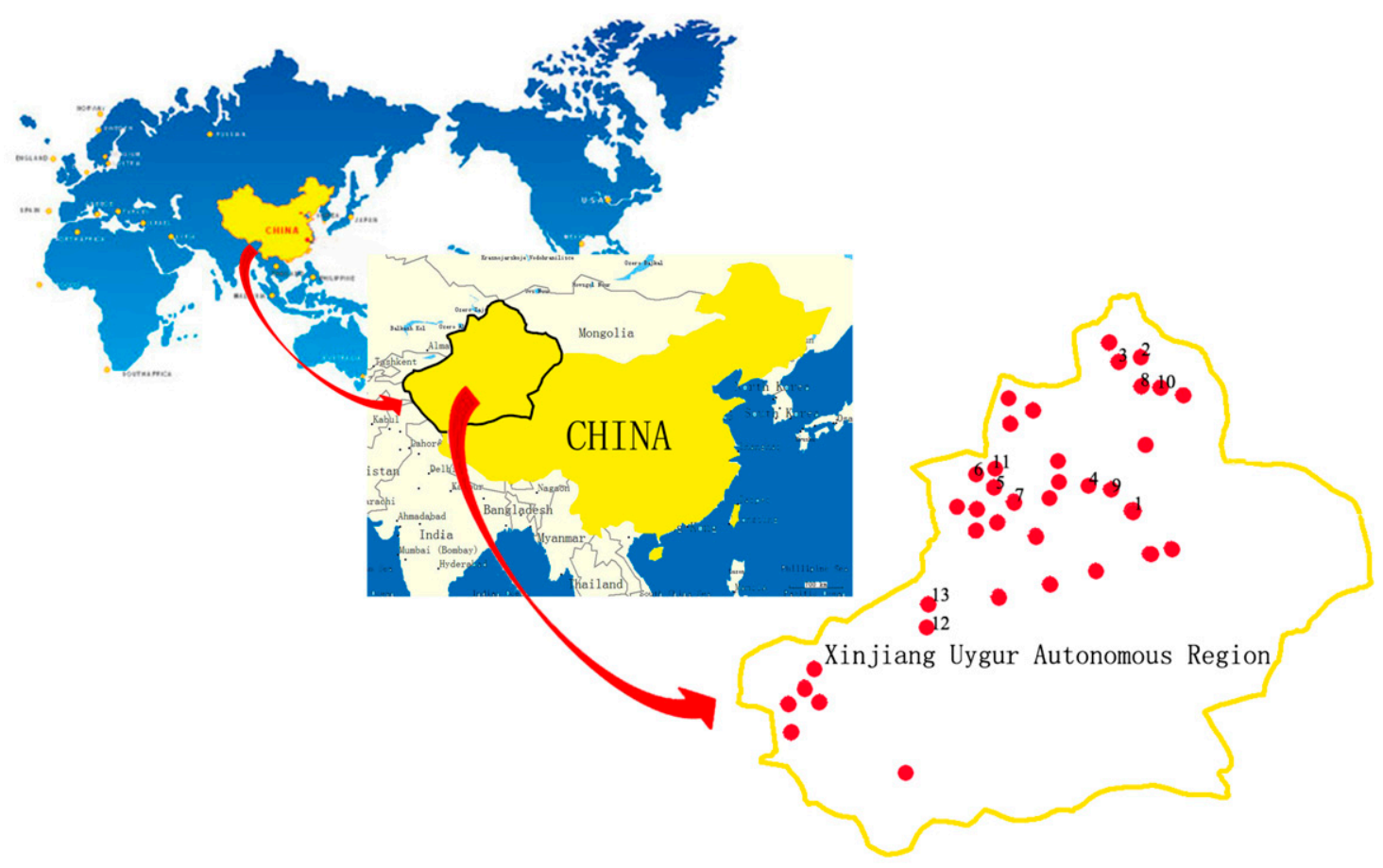

Fig. 1. Location of study sites in Xinjiang, northwestern China (2009-11); $\bullet$ wild Rosa species distributed in Xinjiang, including the 13 studied samples.

Table 1. Rosa taxa in Xinjiang, northwestern China, recorded in Flora of China (Ku and Robertson, 2003) and related cytological data.

\begin{tabular}{lllll}
\hline Subgenus & \multicolumn{1}{c}{ Section } & \multicolumn{1}{c}{ Species } & \multicolumn{1}{c}{ Ploidy } & Karyotype \\
\hline Hulthemia & & R. berberifolia & Diploid & No report \\
Rosa & Pimpinellifoliae & R. spinosissima var. spinosissima & Tetraploid & No report \\
Rosa & Pimpinellifoliae & R. spinosissima var. altaica & Tetraploid & No report \\
Rosa & Pimpinellifoliae & R. kokanica & No report & No report \\
Rosa & Pimpinellifoliae & R. platyacantha & Diploid & No report \\
Rosa & Pimpinellifoliae & R. foetida & No report & No report \\
Rosa & Cinnamomeae & R. beggeriana var. beggeriana & Diploid & $2 n=2 x=6 \mathrm{~m}+8 \mathrm{sm}$ (Yang et al., 2008) \\
Rosa & Cinnamomeae & R. beggeriana var. lioui & Diploid & No report \\
Rosa & Cinnamomeae & R. albertii & No report & No report \\
Rosa & Cinnamomeae & R. acicularis & Tetraploid & No report \\
& & & Octoploid & No report \\
Rosa & Cinnamomeae & R. oxyacantha & Diploid, tetraploid & $2 n=4 x=12 \mathrm{~m}+16 \mathrm{sm}$ (Yang et al., 2008) \\
Rosa & Cinnamomeae & R. laxa var. laxa & Diploid & No report \\
Rosa & Cinnamomeae & R. laxa var. mollis & No report & No report \\
Rosa & Cinnamomeae & R. fedtschenkoana & &
\end{tabular}

development of DNA sequence-based technology in recent years, cytological markers remain useful for plant identification, evaluation of biodiversity, and the study of plant evolution. It has long been known that some wild species, mainly diploids, represent potentially valuable genetic resources, especially for disease resistance. The wild Rosa species that have been reported are euploids with chromosome numbers ranging from $2 n=2 x=$ 14 to $2 n=10 x=70$ (Crane and Byrne, 2003; Darlington and Wylie, 1955; Jian et al., 2010a, 2012; Ma et al., 1997; Malecka et al., 1990; Malecka and Popek, 1984), and an accurate measurement of ploidy appears to be of enormous significance for cross-breeding. The various ploidy groups are not completely cut off from one another; however, the rose breeder who confines his or her hybridization to one ploidy group of species or botanical varieties will find his or her path smoothed and his or her aims more quickly achieved (Percy, 1964).
Karyotype analysis is a traditional cytogenetic first step in the comparison of genomes among related species (Crane and Byrne, 2003) under the usually correct presumption that karyotypic differences can affect meiotic chromosome pairing and hybrid fertility. Although the karyotypic variation within Rosa implies a rich genetic resource for rose breeding, it also frequently impedes breeding progress because of cross-incompatibility and hybrid sterility. Hence, elucidation of the karyotype and the physical structure of chromosomes can rationalize and accelerate the exploitation of genetic variation from wild relatives of crops (Baenziger et al., 2006). What is more, the results might be helpful in elucidation of some taxonomical problems and relations between particular species within this highly differentiated genus.

Therefore, a 3-year investigation on wild Rosa species in Xinjiang was conducted from 2009 to 2011 with two objectives: 


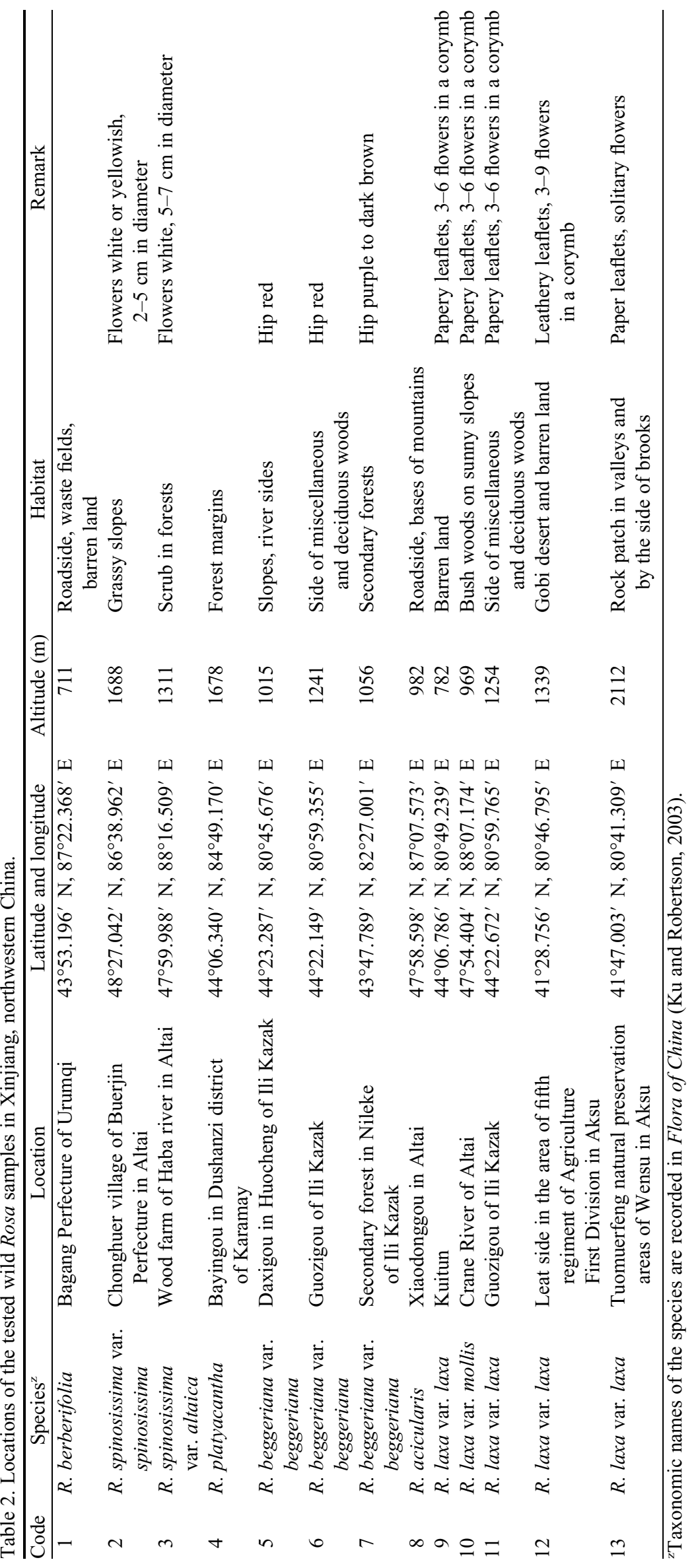


1) to learn more details of the wild Rosa species and to compare species and botanical varieties on the basis of morphological and cytological characters; and 2) to exploit useful traits of wild Rosa species and identify candidate species for breeding strategies. In this article, the chromosome number and karyotype analysis are reported for 13 samples of seven wild Rosa taxa from different subregions of Xinjiang.

\section{Materials and Methods}

Materials. All the test samples were collected from the original sources in Xinjiang (Table 2), and the wild Rosa species were identified carefully according to the Flora of China (Ku and Robertson, 2003). Additional variants, recorded in the primary literature (Bao, 1993; Han, 1995; Liu, 1993; Liu and Cong, 2000; Ma and Chen, 1990; Yu et al., 1985, 2011), were surveyed and analyzed together. Table 2 lists the authorities for taxonomic names used in this article.

Methods. Shoot tips $\approx 1 \mathrm{~cm}$ long were collected from the vigorously growing plants $\approx 0830 \mathrm{HR}$. The materials were treated first with $0.002 \mathrm{~mol} \cdot \mathrm{L}^{-1} 8$-hydroxyquinoline for $50 \mathrm{~min}$ at $25{ }^{\circ} \mathrm{C}$ and then fixed for $4 \mathrm{~h}$ in fresh Farmer's fixative (1:3 glacial acetic acid/absolute alcohol) at $4{ }^{\circ} \mathrm{C}$. Finally the shoot tips were softened with $1 \mathrm{M}$ hydrochloric acid at $55^{\circ} \mathrm{C}$ for $10 \mathrm{~min}$ and stained for $10 \mathrm{~min}$ with carbol-fuchsin before being squashed between a glass slide and a coverslip. The images were captured by a charge-coupled device (CCD) camera (ProgRes C5; Analytik Jena, Jena, Germany) attached to a microscope (Axio Scope, A1; Carl Zeiss, Oberkochen, Germany) and chromosome numbers were counted.

DAta AnAlysis. For each genotype, at least 10 cells with good chromosomal dispersion were selected, counted, photographed, and analyzed. Images were processed with VideoTestKaryo (Version 3.1; VideoTest, Saint-Petersburg, Russia), Image-Pro Plus (Version 6.0; Media Cybernetics, Rockville, MD) and Photoshop (Version CS2; Adobe, San Jose, CA). The centromeric position was classified as median (m), submedian (sm), or subterminal (st) according to Levan et al. (1964). The symmetry of karyotype was classified strictly according to the method of Stebbins (1971). The ratio of the sum of the length of
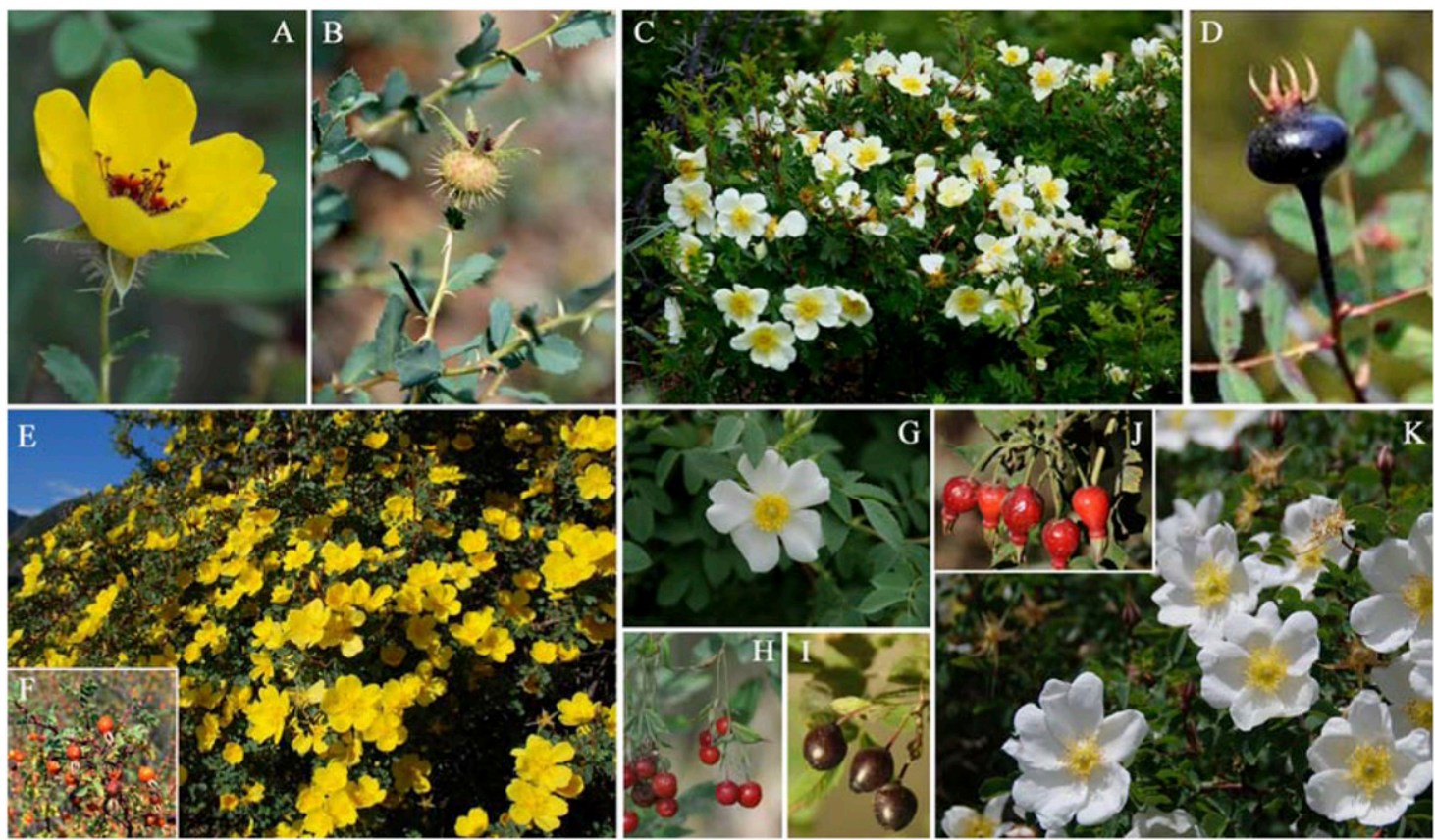

Fig. 2. Flowers and hips of some studied wild Rosa species in Xinjiang, northwestern China: (A) flower of R. berberifolia (sample 1), (B) hip of R. berberifolia (sample 1), (C) flowers of $R$. spinosissima var. altaica (sample 3), (D) hip of $R$. spinosissima var. altaica (sample 3), (E) flowers of $R$. platyacantha (sample 4), (F) hip of $R$. platyacantha (sample 4), (G) flower of $R$. beggeriana var. beggeriana (sample 5), (H-I) hips of $R$. beggeriana var. beggeriana (samples 5 and 7 ), (J) hips of R. laxa var. laxa (sample 11), (K) flowers of R. laxa var. laxa (sample 11).
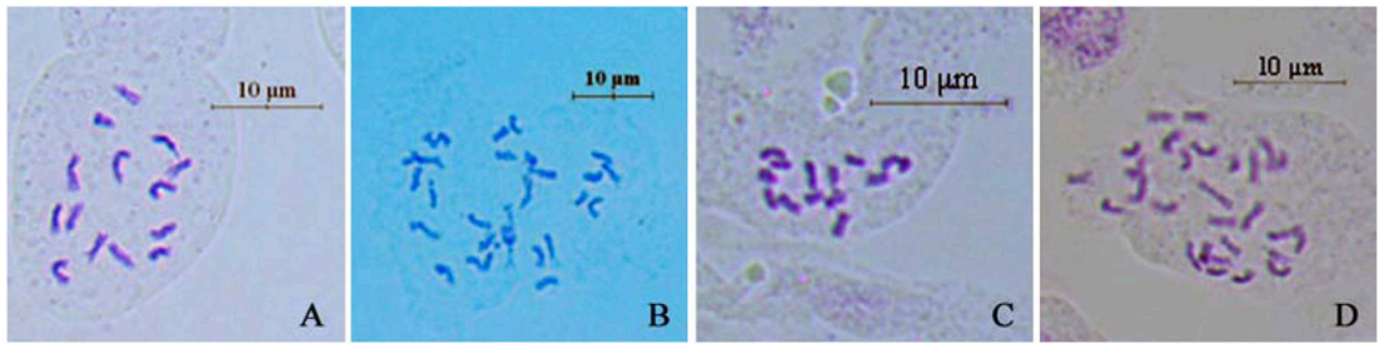

Fig. 3. Metaphase chromosomes of four wild Rosa samples in Xinjiang, northwestern China. (A) R. berberifolia (sample 1), (B) R. Platyacantha (sample 4), (C) R. beggeriana var. beggeriana (sample 5), (D) R. laxa var. laxa (sample 11). 

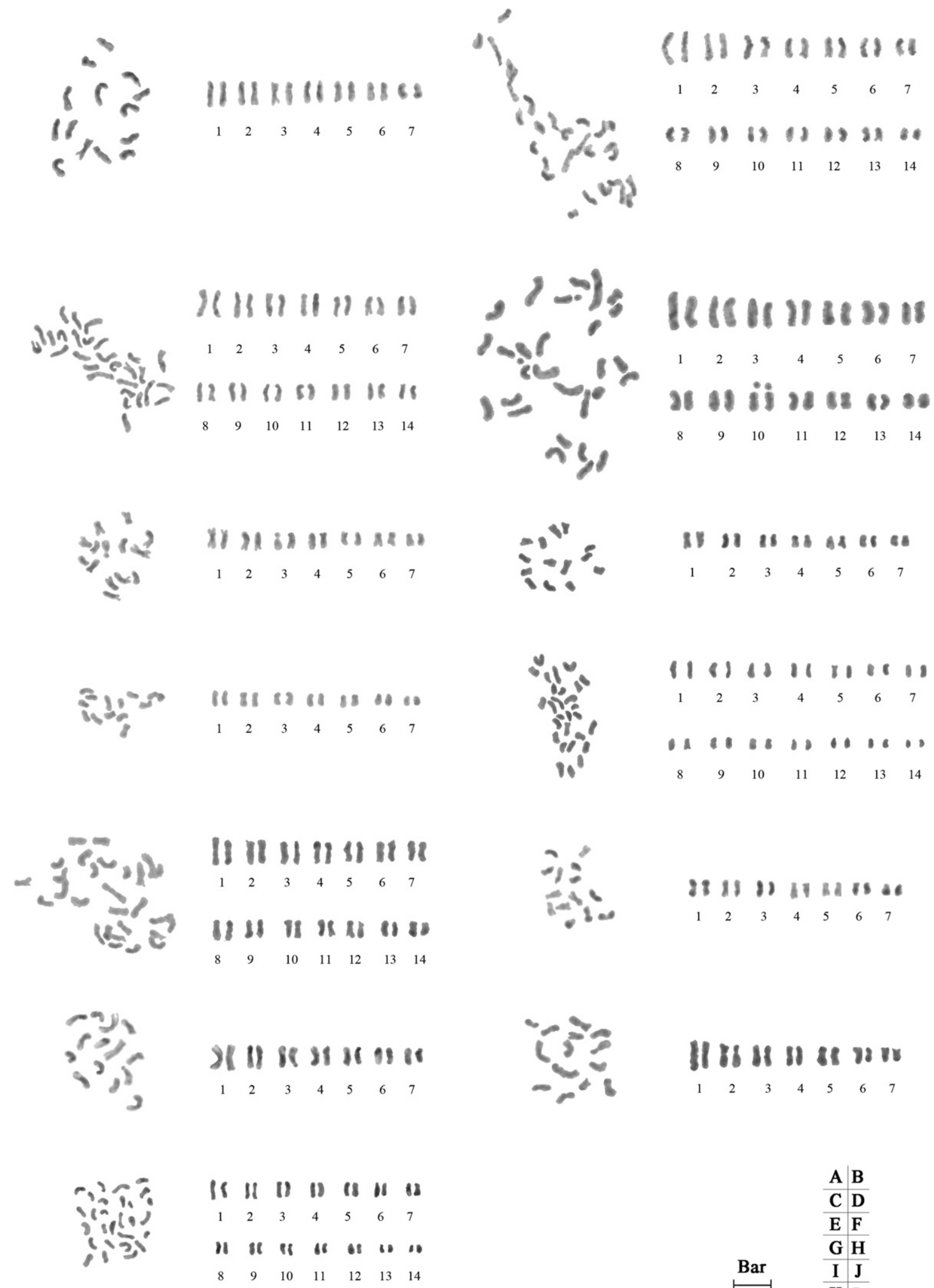

Fig. 4. Chromosome karyotypes of studied Rosa species in Xinjiang, northwestern China (bar $=5 \mu \mathrm{m})$ : (A) R. berberifolia (sample 1), (B) R. spinosissima var. spinosissima (sample 2), (C) R. spinosissima var. altaica (sample 3), (D) $R$. platyacantha (sample 4), (E-G) R. beggeriana var. beggeriana (samples 5, 6, 7), (H) $R$. acicularis (sample 8), (I) R. laxa var. laxa (sample 9), (J) R. laxa var. mollis (sample 10), (K-M) R. laxa var. laxa (samples 11, 12, 13). 
the long arms of individual chromosomes to the total haploid length of the chromosome complement (AS.K\%) was measured on the basis of Arano (1963), and index of relative length (IRL) and relative length composition of genome (RLC) were calculated in accordance with Kuo et al. (1972).

\section{Results}

Four spread metaphase of the studied Rosa taxa are shown in Fig. 3. Karyotypes of all studied Rosa species are shown in Fig. 4. Parameters of chromosomes of studied species are listed in Table 3. No aneuploidy and no odd ploidy were observed in this study.

KARYOTYPE ANALYSIS OF $R$. BERBERIFOLIA. This morphologically distinctive species was diploid with a karyotype formula of $12 \mathrm{~m}+2 \mathrm{sm}$. The genome were composed of all four types of chromosomes [i.e., long (L), medium long (M2), medium short (M1), and short (S)], which made the constitution of relative length $2 n=2 \mathrm{~L}+6 \mathrm{M} 2+4 \mathrm{M} 1+2 \mathrm{~S}$. The centromere index ranged from $35.43 \%$ to $46.16 \%$, and the asymmetry index was $59.82 \%$. The length ratio of longest to shortest chromosome (Lt/St) was 1.68. With none of the chromosomes' arm ratios larger than 2, the karyotype of $R$. berberifolia belonged to $1 \mathrm{~A}$.

KARYOTYPE ANALYSIS OF $\boldsymbol{R}$. SPINOSISSIMA. In all metaphase plates analyzed in $R$. spinosissima, a tetraploid chromosome number $(2 n=4 x=28)$ was observed. However, chromosome morphology differed between $R$. spinosissima var. spinosissima and $R$. spinosissima var. altaica. All chromosomes of var. spinosissima were metacentric, and the constitution of relative length was $2 n=2 \mathrm{~L}+10 \mathrm{M} 2+10 \mathrm{M} 1+4 \mathrm{~S}$ for $R$. spinosissima var. spinosissima and $2 n=2 \mathrm{~L}+6 \mathrm{M} 2+16 \mathrm{M} 1+2 \mathrm{~S}$ for $R$. spinosissima var. altaica. In addition, $R$. spinosissima var. spinosissima had the largest Lt/St of 2.69, whereas $R$. laxa var. laxa (sample 10) had the smallest Lt/St of only 1.49. The asymmetry index of $R$. spinosissima var. spinosissima, $52.60 \%$, was the smallest from all the studied species.

KARYOTYPE ANALYSIS OF $R$. PLATYACANTHA. The chromosome number for $R$. platyacantha was $2 n=4 x=28$. The genome of this tetraploid species was composed of all four types of chromosomes, which made the constitution of relative length $2 n=4 \mathrm{~L}+10 \mathrm{M} 2+12 \mathrm{M} 1+2 \mathrm{~S}$. Although no satellites were observed in the genomes of most of the wild Rosa species in this study, for $R$. platyacantha, the tenth chromosome pair had a pair of satellites.

KARYOTYPE ANALYSIS OF R. BEGGERIANA VAR. BEGGERIANA. All three tested samples were diploid with exclusively metacentric and submetacentric chromosomes. The constitutions of relative length of samples 5,6 , and 7 were $2 n=2 \mathrm{~L}+6 \mathrm{M} 2+6 \mathrm{M} 1,2 n=$ $2 \mathrm{~L}+2 \mathrm{M} 2+10 \mathrm{M} 1$, and $2 n=2 \mathrm{M} 2+10 \mathrm{M} 1+2 \mathrm{~S}$, respectively. Besides, the asymmetry index of $63.77 \%$ from sample 5 was the largest among all the tested samples.

KARYOTYPE ANALYSIS OF $\boldsymbol{R}$. ACICULARIS. $R$. acicularis was tetraploid with 28 exclusively metacentric and submetacentric chromosomes $(2 n=4 x=28)$. The genome was also composed of all four types of chromosomes, making the constitution of relative length $2 n=4 \mathrm{~L}+8 \mathrm{M} 2+12 \mathrm{M} 1+4 \mathrm{~S}$. The $\mathrm{Lt} / \mathrm{St}$ ratio was 2.24. Therefore, with the arm ratio larger than two for one pair of chromosomes, the karyotype of this taxon was $2 \mathrm{~B}$.

KARYOTYPE ANALYSIS OF $\boldsymbol{R}$. LAXA. The five $R$. laxa samples were divided into diploids $(2 n=2 x=14)$ and tetraploids $(2 n=$ $4 x=28$ ) with values of the asymmetry index from $55.14 \%$ to $60.11 \%$. The karyotypes of all five samples were made up of $\mathrm{m}$ and sm chromosomes, which included 1A, 2A, and 1B. The ideograms of the five tested samples for this species are illustrated in Figure 5.

\section{Discussion}

The basic chromosome number is relevant to the systematic position of a taxon at high taxonomic levels (Raven, 1975). Wild Rosa species comprise a polyploid complex with a base chromosome number of seven. Not surprisingly, the present investigations regarding the base chromosome number agree completely with previous reports.

As shown in Table 3, R. berberifolia and $R$. beggeriana var. beggeriana were found to be diploid, whereas $R$. spinosissima var. spinosissima, $R$. spinosissima var. altaica, $R$. platyacantha, and $R$. acicularis were found to be tetraploid. Because previous chromosome counts of $R$. platyacantha were diploid $(\mathrm{Ku}$ and Robertson, 2003), this species has two ploidy levels in its area of distribution. The aforementioned tetraploid species had more advanced karyotypes of $1 \mathrm{~B}$ or $2 \mathrm{~B}$ than the diploids had. There is no direct evolutionary relationship between the variations of the

Table 3. Parameters of chromosomes for 13 tested wild Rosa samples in Xinjiang, northwestern China.

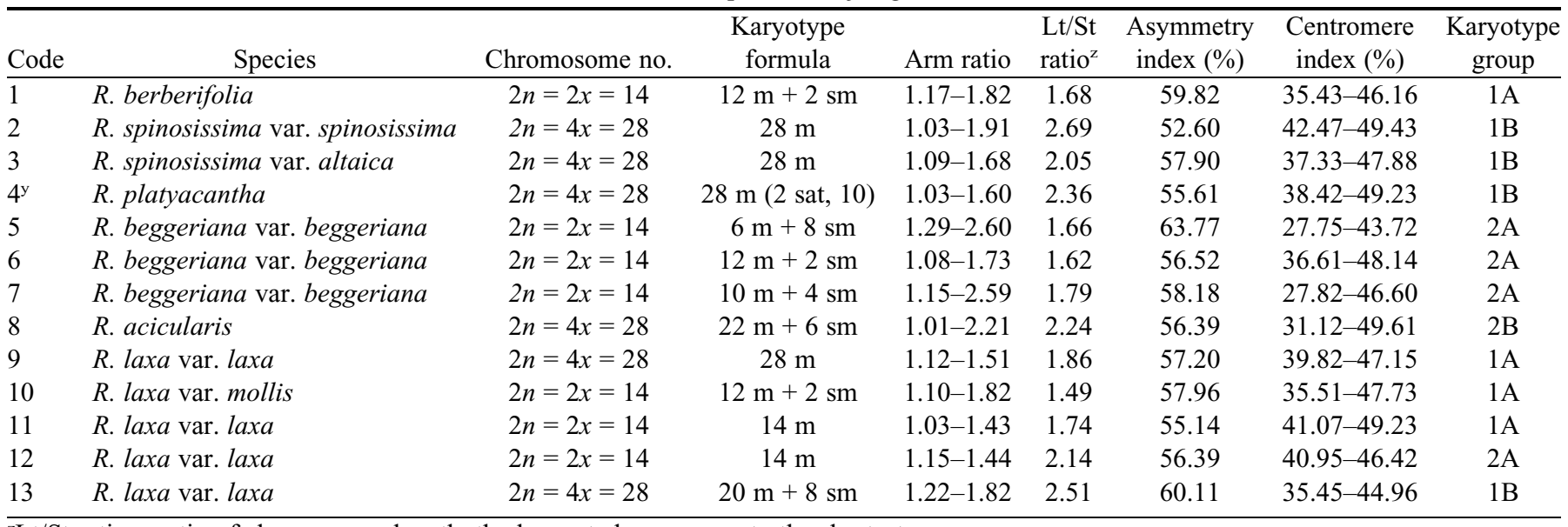

${ }^{\mathrm{z}} \mathrm{Lt} / \mathrm{St}$ ratio $=$ ratio of chromosome length, the longest chromosome to the shortest one.

${ }^{\mathrm{y}}$ The length of satellites is not included in the chromosome length. 


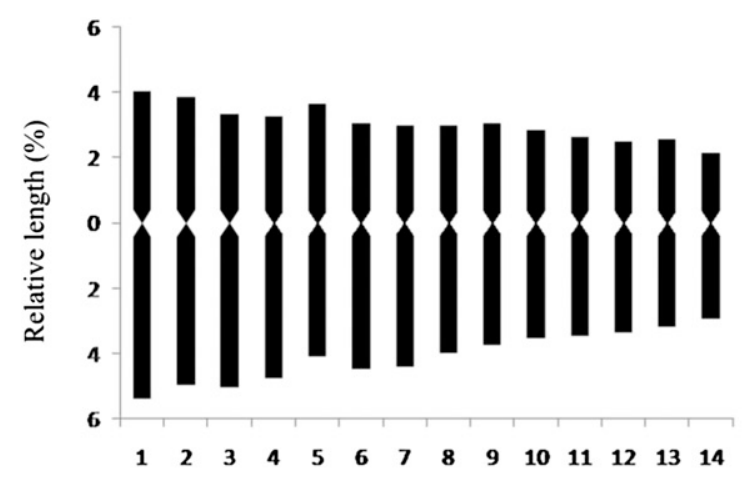

Chromosome code

Constitution of relative length: $4 \mathrm{~L}+10 \mathrm{M} 2+14 \mathrm{M} 1$

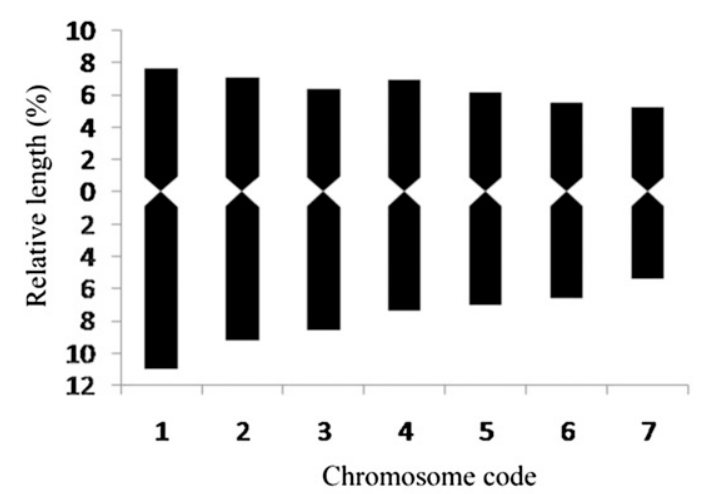

Constitution of relative length: $2 \mathrm{~L}+6 \mathrm{M} 2+6 \mathrm{M} 1$

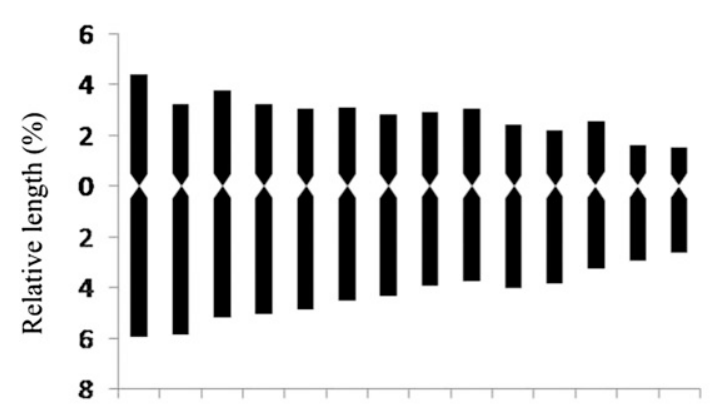

$\begin{array}{lllllllllllllll}1 & 2 & 3 & 4 & 5 & 6 & 7 & 8 & 9 & 10 & 11 & 12 & 13 & 14\end{array}$

Chromosome code

Constitution of relative length: $6 \mathrm{~L}+8 \mathrm{M} 2+14 \mathrm{M} 1$

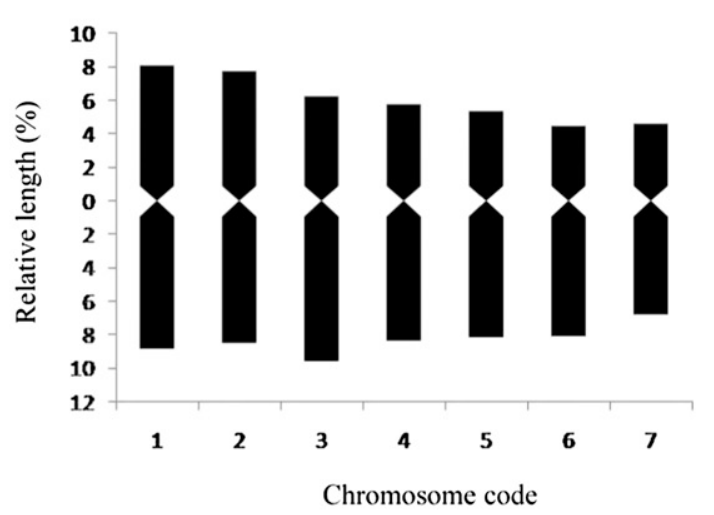

Constitution of relative length: $6 \mathrm{M} 2+8 \mathrm{M} 1$

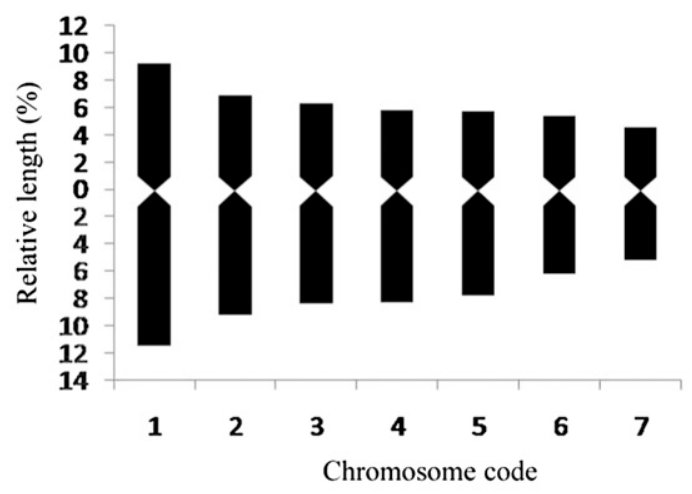

Constitution of relative length: $2 \mathrm{~L}+4 \mathrm{M} 2+8 \mathrm{M} 1$

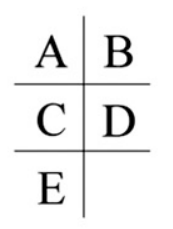

Fig. 5. Ideograms of five tested samples of Rosa laxa from different location in Xinjiang, northwestern China (A-E represent samples 9-13, respectively).

ploidy level and the species, as we can see from the tetraploid sample 9, which possessed a very symmetric karyotype. This phenomenon was also observed by Luo et al. (2009) in traditional Chinese rose cultivars.

It is believed that wild Rosa species in China and Chinese traditional rose cultivars are all supposed to exhibit karyological diversity (Jian et al., 2010b, 2012; Luo et al., 2009; Yang, 2009; Yang et al., 2008), and our study confirmed those previous reports. However, in strong contrast to the present study, previous authors (Jian et al., 2012; Song and Li, 1989) have reported that only two types of karyotypes (1A, 2A) occur in the wild Rosa species, whereas four types of karyotypes (1A, 2A, 1B, 2B) were found in our research. However, among the studied samples, all of the karyotypes consisted of metacentric or metacentric with submetacentric chromosomes. Meanwhile, lack of satellites implies terminal position of the nucleolar organizer region, not absence of at least one nucleolar organizer region.

Many species occur at only one ploidy level, but a few form a polyploid series (Wissemann, 2003). Available results have divided R. laxa on the basis of ploidy (Cairns et al., 2000; Yang, 2009; Yang et al., 2008; Zhu, 2011). In this study, we found diploid and tetraploid $R$. laxa in different floristic regions. Meanwhile, $R$. laxa is obviously variable in morphology. Guo (2010) studied the natural populations of $R$. laxa in the Tianshan Mountains and believed the genetic diversity of $R$. laxa was abundant both within populations and among populations. In this study, the tetraploid karyotype of sample 13 was distinct in having the highest asymmetry index and the most evolved arm 


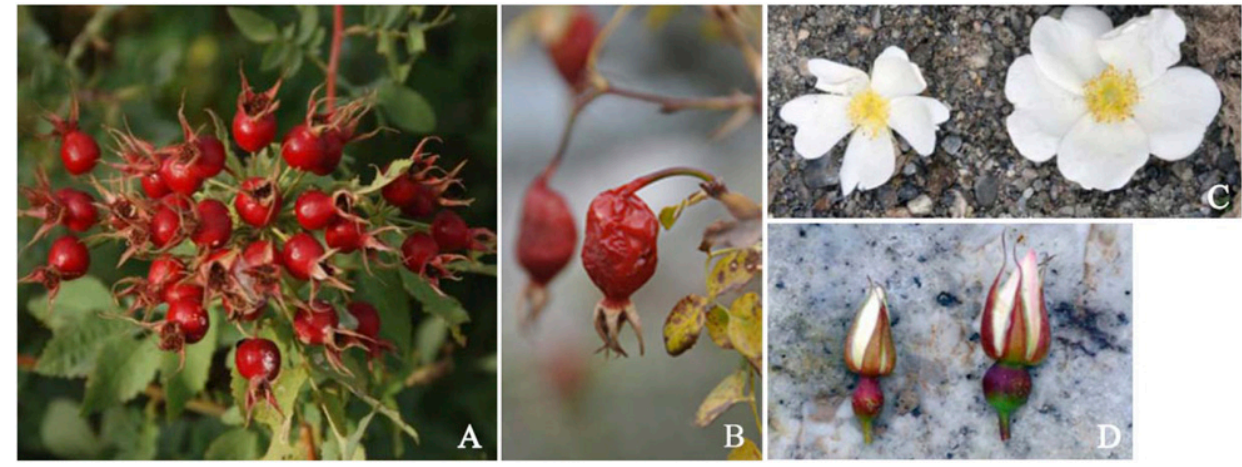

Fig. 6. Morphological differences of Rosa laxa between sample 10 and sample 13: (A) hip of sample 10, (B) hip of sample 13, (C-D) comparison of the single flower and flower bud (left = sample 10, right $=$ sample 13). conditions that led to the creation of new adaptive traits. The Tomur National Nature Reserve lies on the southern flank of the Tianshan Mountains (lat. $41^{\circ} 40^{\prime} \mathrm{N}$ to $42^{\circ} 02^{\prime}$ $\mathrm{N}$, long. $80^{\circ} 07^{\prime} \mathrm{E}$ to $80^{\circ} 52^{\prime} \mathrm{E}$ ) in Wensu County, which is one of the biggest alpine nature reserves in China. The mean elevation of the reserve is $4000 \mathrm{~m}$ and its climate is cold and arid with a mean annual rainfall 600 to $700 \mathrm{~mm}$. R. laxa in Tomur exhibits tetraploidy, in accordance with the aforementioned generalization that extreme habitats promote the evolution of polyploidy.

ratios among all taxa within $R$. laxa. Besides, this taxon differs from typical $R$. laxa (sample 10) in the presence of the even bigger flower and hip size as well as the solitary flower rather than three to six flowers in a corymb (Fig. 6). These obvious morphological differences were reported by Liu Shixia (2000), who recognized this taxon as a new botanical variety of $R$. laxa, namely $R$. laxa var. tomurensis. Taking into consideration this description and the karyological data, along with the precedent that Lewis (1959) recognized the two morphologically distinct ploidies in $R$. acicularis as distinct subspecies, we support the previous view by Liu Shixia that this tetraploid taxon, $R$. laxa var. tomurensis, should be treated as a distinct botanical variety of $R$. laxa.

However, sample 12, which has leathery leaflets, was regarded as another botanical variety, $R$. laxa var. kaschgarica, which had already been recognized in Flora Xinjiangensis (Han, 1995). However, considering only one morphological difference as well as the same pattern of their karyological differentiation, it seems that further study is needed to ascertain whether it should be treated as a botanical variety of $R$. laxa or promoted to a specific rank. Because the karyotypes differed little, the hip color of $R$. beggeriana (Fig. $2 \mathrm{G}-\mathrm{H}$ ) was not regarded as a species diagnostic morphological trait in this study.

The classification of the genus Rosa has been disputed for a long time. Previous studies mainly focused on morphological characters, germplasm collection, and germplasm preservation. Moreover, the morphological descriptions of wild Rosa species are always complicated and often present problems in the precise identification of the species and especially their botanical varieties. The chromosome counts of genus Rosa have varied and can be used in its taxonomy (Ghanbari et al., n.d.). From our point of view, the chromosome morphology or karyotype could be a useful tool for identifying species, botanical varieties, and populations, investigating their genetic relationships and better understanding their evolutionary history. However, it is unlikely that further, more detailed karyotype analysis will change the major sectional alignments in Rosa.

The increase in chromosome number and consequent genome redundancy created by polyploidy has long been recognized as a prominent feature in the evolution of flowering plants (Levin, 2002; Stebbins, 1971). In Plant Speciation, Grant (1981) devoted five chapters ( $15 \%$ of the total text) to polyploidy, reflecting the importance of the topic both to the author and to plant biologists. Alpine and arctic floras have been regarded to have high frequencies of polyploidy (Brochmann et al., 2004; Ohba, 1988). Species in these restricted areas had to face harsh environmental
Similarly, other species of Rosa section Cinnamomeae are polyploidy at high altitude in Yunnan Province, southwestern China (Jian et al., 2012). Thus, a comprehensive study would require a greater number of population samples that represent all the variations and the full range of habitats in which $R$. laxa occurs. What is more, the results indicate that different ploidy levels are associated with different regions and habitats where the germplasm resources grow.

Unfortunately, there is little information in the literature focused on the use of wild Rosa species in Xinjiang, although these species were found to have many desirable traits (Chen, 1997; Muller et al., 2008), partly because of their complex genetic background. This information gap should be addressed as early as possible. Although not discussed in this article, attention must be given to the relationship between the ploidy difference and the success of distant hybridization. Detailed analysis of the Solanum polyploid series, where the endosperm behavior has been mapped out over numerous species in the primary and secondary gene pools of potato (Carputo et al., 2003), suggests that the same evolutionary path may account for the origin and evolution of polyploidy taxa in Rosa. We infer from the text and our hybridization data (unpublished) that Rosa has an endosperm balance requirement of two maternal genomes to one paternal genome for successful growth of the endosperm early in seed development. Further research in the likely existence of endosperm balance numbers in Rosa should also be conducted.

The cytological data would supply chromosomal proofs not only for the taxonomy and evolution of genus Rosa, but also facilitate the exploitation of useful traits of wild Rosa species in breeding strategies. As we know, polyploids are often associated with particular characteristics such as increased heterozygosity and gene redundancy, proportional increases in gene expression, increase in cell and body size, changes in stomata size, and environmental stress tolerance (Coughlan, 2012; Levin, 1983).

Different ploidy levels among the $R$. laxa var. laxa (samples $9,10,11)$ and the botanical varieties with desirable traits (samples 12,13) could provide diverse breeding materials. For example, with leathery leaflets, sample 12 could provide potential resistance against the powdery mildew and downy mildew (Botrytis cinerea). Tetraploid samples 9 and 13, which have the same ploidy level with most of the modern rose cultivars, will expectedly improve the success rate of distant hybridization. In sum, a better understanding of the cytological data that contribute to breeding systems and desired traits will definitely lead to improved modern rose cultivars. 


\section{Literature Cited}

Arano, H. 1963. Cytological studies in subfamily Carduoideae (Compositae) of Japan IX. Bot. Mag. Tokyo 76:32-39.

Baenziger, P.S., W.K. Russell, G.L. Graef, and B.T. Campbell. 2006. 50 years of crop breeding, genetics and cytology. Crop Sci. 46:2230 2244

Bao, Z.Y. 1993. Studies on the wild rose resources in North China on the kinetics of the delayed fluorescence \& ultraweak chemiluminescence from Rosa spp. \& cvs. PhD diss., Beijing For. Univ., Beijing, China.

Brichet, H. 2003. Distribution and ecology/continental Asian and Japan, p. 204-215. In: Roberts, A., T. Debener, and S. Gudin (eds.). Encyclopedia of rose science. Elsevier, Oxford, UK.

Brochmann, C., A.K. Brysting, I.G. Alsos, L. Borgen, H.H. Grundt, A.C. Scheen, and R. Elven. 2004. Polyploidy in arctic plants. Biol. J. Linn. Soc. Lond. 82:521-536.

Cairns, T., M. Young, J. Adams, and B. Edberg. 2000. Modern roses XI: The world encyclopedia of roses. Academic Press, San Diego, CA.

Carputo, D., L. Frusciante, and S.J. Peloquin. 2003. The role of $2 n$ gametes and endosperm balance number in the origin and evolution of polyploids in the tuber-bearing solanums. Genetics 163:287-294.

Chen, J.Y. 1997. To select more new species of Rosa cvs. in China.

Flower Plant Penjing 14:10-11.

Coughlan, J. 2012. Mechanisms for range size and distribution variation in the polyploid complex black-fruited hawthorn (Crataegus series Douglasianae): Biogeographic implications for the maintenance of cytotype diversity. PhD. diss., Univ. Toronto, Toronto, Canada.

Crane, Y.M. and D.H. Byrne. 2003. Karyology, p. 267-285. In: Roberts, A., T. Debener, and S. Gudin (eds.). Encyclopedia of rose science. Elsevier, Oxford, UK.

Darlington, C.D. and A.P. Wylie. 1955. Chromosome atlas of flowering plants. George Allen Unwin, London, UK. p. 134-138.

Ghanbari, A., M. Sahebi, S.R. Tabai-Aghdai, S. Ghaffaripour, and B.A. Siahsar. n.d. Chromosome and somatic karyotype analysis in some genotypes of Rosa damascena mill (Rosaceae). 18 Aug. 2013. $<$ http://www.economia.uniroma2.it/conferenze/icabr2005/papers/ ghaffari_paper1.pdf $>$.

Grant, V. 1981. Plant speciation. Columbia Univ. Press, New York, NY. Guo, N. 2010. Genetic diversity of natural populations of Rosa laxa Retz. and Rosa platyacantha Schrenk. Diss., Chinese Acad. Agr. Sci., Beijing, China.

Han, Y.L. 1995. Rosa Linnaeus, p. 335-347. In: Flora Xinjiangensis. Vol. 2(2). Xinjiang Sci. Technol. Hygiene Publ. House, Urumqi, China.

Jian, H.Y., H. Zhang, K.X. Tang, S.F. Li, Q.G. Wang, X.Q. Qiu, and H.J. Yan. 2010a. Decaploidy in Rosa praelucens Byhouwer (Rosaceae) endemic to Zhongdian Plateau, Yunnan, China. Caryologia 63:162-167.

Jian, H.Y., H. Zhang, T. Zhang, S.F. Li, Q.G. Wang, X.Q. Qiu, and H.J. Yan. 2010b. Karyotype analysis of different varieties of Rosa odorata Sweet. J. Plant Genet. Resources 11:457-461.

Jian, H.Y., T. Zhang, Q.G. Wang, S.B. Li, H. Zhang, and K.X. Tang. 2012. Karyological diversity of wild Rosa in Yunnan, southwestern China. Genet. Resources Crop Evol. 60:115-127.

Ku, T.C. and K.R. Robertson. 2003. Rosa (Rosaceae), p. 339-381. In: Wu, Z.Y. and P.H. Raven (eds.). Flora of China. Vol. 9. Sci. Press, Beijing, China.

Kuo, S.R., T.T. Wang, and T.C. Huang. 1972. Karyotype analysis of some Formosan gymnosperms. Taiwania 17:66-80.

Levan, A., K. Fredga, and A. Sandberg. 1964. Nomenclature for centromeric position on chromosomes. Hereditas 52:201-220.

Levin, D.A. 1983. Polyploidy and novelty in flowering plants. Amer. Nat. 122:1-25.

Levin, D.A. 2002. The role of chromosomal change in plant evolution. Oxford Univ. Press, New York, NY.
Lewis, W.H. 1959. A monograph of the genus Rosa in North America I. R. acicularis. Brittonia 11:1-24.

Liu, S.X. 1993. Rosa in Xinjiang. Plants 6:19-21.

Liu, S.X. and Z.F. Cong. 2000. Rosa in Xinjiang. Xinjiang Sci. Technol. Hygiene Publ. House, Urumqi, China.

Luo, L., Q.X. Zhang, J.R. Bai, H.T. Pan, H. Li, and Q. Wang. 2009. Karyotype analysis of sixteen Chinese traditional rose cultivars. J. Beijing For. Univ. 31:90-95.

Ma, Y. and J.Y. Chen. 1990. Germplasm resources of Rosa in northwest of China. Chinese Landscape Architecture 6:50-51 [in Chinese].

Ma, Y. and J.Y. Chen. 1991. Chromosome studies of seven roses. J. Fujian For. College 11:215-218 [in Chinese with English abstract].

Ma, Y. and J.Y. Chen. 1992. Chromosome studies of 6 species of Rosa in China. Guihaia 12:333-336 [in Chinese with English abstract].

Ma, Y., C.F. Crane, and D.H. Byrne. 1997. Karyotypic relationships among some Rosa species. Caryologia 50:317-326.

Macphail, V.J. and P.G. Kevan. 2009. Review of the breeding systems of wild roses (Rosa spp.), p. 1-13. In: Floriculture and ornamental biotechnology. Global Sci. Books, Isleworth, UK.

Malecka, J. and R. Popek. 1984. Karyological studies in the Polish representatives of the genus Rosa L. II. Acta Biol. Cracov. Ser.; Bot. XXVI:43-54.

Malecka, J., R. Popek, and G. Facsar. 1990. Cyto-taxonomical studies in the genus Rosa L. The representatives from Hungary. Acta Biol. Cracov. Ser.; Bot. XXXII:189-195.

Muller, D.S., M.L. Gleason, N.P. Howell, and E.M. Moran. 2008. Evaluation of Griffith Buck roses for resistance to black spot. HortTechnology 18:588-591.

Ohba, H. 1988. The alpine flora of the Nepal Himalayas: An introductory note, p. 19-46. In: Ohba, H. and S.B. Malla (eds.). The Himalayan plants. Vol. 1. Tokyo Univ. Press, Tokyo, Japan.

Percy, H.W. 1964. Chromosome number in roses. Amer. Rose Annu. 49:173-175.

Quest-Ritson, C. and B. Quest-Ritson. 2003. The American Rose Society encyclopedia of roses. DK Publ., New York, NY.

Raven, P.H. 1975. The bases of angiosperm phylogeny: Cytology. Ann. Missouri Bot. Gardens 62:724-764.

Rehder, A. 1940. Manual of cultivated trees and shrubs. 2nd Ed. MacMillan, New York, NY. p. 996-998.

Song, R.J. and H.Q. Li. 1989. Analyses on karyotypes of Roxburgh rose. Acta Bot. Sin. 31:155-157.

Stebbins, G.L. 1971. Chromosome evolution in higher plants. Edward Arnold, London, UK.

Wissemann, V. 2003. Classification/conventional taxonomy (wild roses), p. 111-116. In: Roberts, A., T. Debener, and S. Gudin (eds.). Encyclopedia of rose science. Elsevier, Oxford, UK.

Yang, SH. 2009. Studies on germination characteristics of seeds and karyotype of Rosa beggeriana Schrenk and Rosa laxa Retz. PhD diss., Southwest For. Univ., Chongqing, China.

Yang, SH., J. Wang, T.T. Wang, S.H. Yang, W.Y. Ge, N. Guo, and H. Ge. 2008. Karyotype analysis of natural populations of Rosa laxa Retz. and Rosa platyacantha Schrenk. Abstr. Symp. Horticultural Ploidy and Genetic Improvement. Chinese Soc. Hort. Sci., Beijing, China. p. 55 (abstr.).

Yu, CH., L. Luo, Y.H. Wang, J. Liu, H.T. Pan, and Q.X. Zhang. 2011. Discussion and analysis of the karyotype of Rosa laxa in Xinjiang. Acta Botanica Boreali-Occidentalia Sinica 31:2459-2463.

$\mathrm{Yu}$, T.T., T.C. Ku, C.L. Li, and L.T. Lu. 1985. Rosa Linnaeus. Flora Reipublicae Popularis Sinicae 37:360-409.

Zlesak, D.C. 2006. Rose $\times$ hybrida L, p. 695-738. In: Anderson, N.O. (ed.). Flower breeding and genetics-Issues, challenges and opportunities for the $21^{\text {st }}$ century. Springer, Dordrecht, The Netherlands.

Zlesak, D.C., K. Zuzek, and S. Hokanson. 2007. A dominant male sterility gene, RSMS1, derived from female Rosa setigera Mich. and its introgression into modern roses. HortScience 42:915-916 (abstr.).

Zhu, P.F. 2011. Breeding technology of the important flowers. Beijing Normal Univ. Publ. Group, Beijing, China. 